\title{
Volatilized extraterrestrial Zn isotope signatures in marine and terrestrial K-Pg boundary sites
}

\author{
Ryan Mathur1, Marissa Spencer2, Brandon \\ Mahon3, Linda Godfrey4, Matthew Garb5, \\ Francisca E. Oboh-Ikuenobe2, Neil Landman6 \\ 1Juniata College, Huntingdon PA mathurr@juniata.edu \\ 2 Missouri S\&T, Rolla, MO ikuenobe@mst.edu \\ 3 James Cook University, Townsville Qld \\ brandon.mahan@jcu.edu.au \\ 4 Rutgers Unviversity, Piscataway, NJ \\ godfrey@marine.rutgers.edu \\ 5CUNY, Brooklyn, NY mgarb@ brooklyn.cuny.edu \\ ${ }_{6}$ Division of Paleontology, American Museum of Natural \\ History, NY landman@amnh.org
}

$\mathrm{Zn}$ isotopes and concentrations were measured in four well-studied K-Pg boundary sites in both terrestrial and marine settings. Higher $\mathrm{Zn}$ isotope values occur in the boundary sediments in comparison to the surrounding sediments. Interpretation of the $\mathrm{Zn}$ isotope values in the marine sediments is complex but can be explained by a variety of hypotheses because the values lie within the mean value for continental crust. However, the $\mathrm{Zn}$ isotope values measured from terrestrial depositional environments are slightly greater than carbonaceous chondrites and trend toward tektites. No Earth-derived process imparts this signature onto rocks. A simple binary mixture of two end-member compositions that most likely compose the majority of $\mathrm{Zn}$ in the boundary sediment, a carbonaceous chondrite component and tektites, explain the measured value. Therefore, the evidence supports the notion that sediment within the boundary originated from extraterrestrial sources mixed with materials that changed due to volatization induced by the meteor strike. 